https://doi.org/10.23941/ejpe.v12i2.453

\title{
Review of Thomas Mulligan's Justice and the Meritocratic State. New York, NY: Routledge, 2018, 225 pp.
}

\author{
ANDREA KLONSCHINSKI
}

Kiel University (CAU)

\section{INTRODUCTION}

Suppose you apply for a job, are invited for an interview, but eventually another person gets the job. Since this person is less qualified for the position than you are, you feel wronged. After all, you, the most meritorious applicant, would have deserved the job! Is this reaction merely an expression of hurt feelings and expectations or does it point to an injustice? Does the most meritorious person have a moral claim to be hired so that the employer violates a duty by not hiring her or him? Thomas Mulligan thinks so. According to him, justice requires that "we treat people for who they are and what they have done" (8) so that everyone gets what he or she deserves. The proper economic system for reaching this goal is a meritocracy, which rests on the central pillars of equality of opportunity, meritocratic hiring, and income responsiveness to merit (89). The argument for meritocracy as a requirement of justice is developed in three parts in Justice and the Meritocratic State. In the first part (1-62), Mulligan meticulously reveals his meta-theoretical assumptions; part two (63-182) presents his core argument for a meritocratic theory of economic justice; and part three (185-216) discusses meritocratic policy measures. In what follows, I summarize the basic thread of the argument and provide some critical comments afterwards.

\section{SUMMARY OF THE ARGUMENT}

Mulligan argues that desert claims come in the form " $X$ deserves $y$ on the basis of $z$ ". That is, they comprise a desert subject $(X)$, a desert object $(y)$, and a desert basis (z) (65ff.). Crucially, the desert basis must be about the desert subject, which means that one cannot deserve anything on the basis of what somebody else has done, and Mulligan takes desert to be strictly backward-looking so that the desert basis must lie in the past (66). The two central desert objects in the economic realm are jobs and income. When it comes to the allocation of jobs, the most important desert basis 
is merit, although it might happen in rare occasions that merit is overridden by other desert bases-for instance, when Adolf Hitler, the most meritorious applicant, is not hired as an art teacher due to the "negative desert basis (genocidal lunacy)" (68). In general, the "Meritocratic Hiring Principle' holds: "when hiring, it is unjust to discriminate against an applicant on grounds irrelevant from the point-of-view of merit" (101). This raises the question as to how 'merit' is to be defined in the first place. Mulligan argues that there is no single answer to this question because merit is a contextual concept, but that "once a context is fixed, it is usually plain what constitutes merit" (102). As a heuristic to define merit in particular cases, he proposes the following: "In a given hiring context, no applicant should be judged on the basis of a characteristic $C$ if it is the case that a reasonable person, familiar with the hiring context regards $C$ as irrelevant from the point-of-view of merit. Put differently, hiring committees should only appeal to characteristics which all reasonable authorities believe are relevant from the point-of-view of merit" (102).

Note that in line with his retrospective concept of desert, Mulligan's justification for meritocratic hiring is strictly backward-looking: the most meritorious person deserves to be hired for reasons of justice, not because of expected efficiency gains or other positive consequences (96, 104). It may even be the case that the most meritorious candidate will not perform excellently in the respective position (69). This conception deviates significantly from others proposed in the literature (see, for example, Daniels 1978; Cavanagh 2002, 43; Segall 2012, 32; Moles 2018, 123). For Mulligan, efficiency and need are not relevant to the demands of justice but enter the scene only when the broader moral question of what should be done is tackled (21-23). That means that option $A$ may be just, but all things considered, $B$ should be done.

Despite the backward-looking justification, meritocracy's positive consequences are pointed out frequently throughout the book. Not only does meritocracy enhance economic efficiency $(88-91,121,158 \mathrm{ff}$.) as a "happy side-effect" (104), it also leads to "achievements of objectively high value", which makes it a perfectionist theory, albeit one that "remains agnostic about what is good and instead establishes a framework under which the good-no matter what it be-can best be pursued" (37). Yet, if neither expected performance, nor efficiency or the enhancement of objective value justify merit-based hiring, what does? Mulligan discusses several reasons (98-101), but it seems that for him, the fundamental normative reason for hiring based on merit consists in the value of an 
autonomous and responsible control over one's life (100, 107ff., 148). Only in a meritocracy, where discrimination on the basis of race or gender is absent (28), can people prepare responsibly for certain jobs by developing the relevant merits (154) and thus have the ability to take their life plans into their own hands (108). If, by contrast, a person is not judged on his merits, he "has lost control over the development of his life and, indeed, his identity" (101). These quotes illustrate why Mulligan calls individual responsibility the "ethos" of meritocracy (6).

When it comes to the distribution of income, this backward-looking justification might suggest making effort the basis of desert. Yet Mulligan argues that although deserved income closely tracks effort, it is also important that effort creates something of economic value, that is, of value for others (128). In addition, this contribution must be meritorious, as is illustrated by the following example. If CEO $A$ were "a brilliant businesswoman and a tireless worker" but failed for reasons unforeseeable to her, whereas $B$ thrived despite her being "stupid, a menace to her employees", $A$ would deserve a higher income (130). This is because " $A$ has all the laudable character traits-and the possession and application of those traits is the essence of desert" (130). Hence, for the purpose of income distribution, the proper desert basis is one's "meritorious contributions to the economy" (130), which amounts to "the additional output" the person provides, that is, her marginal value product (131). Meritocracy may also provide for a social safety-net, but only for the deserving, not the undeserving poor (155-58).

Crucially, meritocracy can only be considered fair against the background of fair equality of opportunity for income, since otherwise personal desert would be undermined (72). Mulligan thus envisages a society in which everyone can become meritorious in the first place (71-73). This requires substantial policy measures, such as the restriction of the family's autonomy and heavy investment in early education (77-82, 203ff.), the taxation of undeserved economic rents (187-190), and the implementation of a robust inheritance tax (192-197). Note at this point that Mulligan rejects the influential Rawlsian idea that, ultimately, nothing is truly deserved (165-182). Our genetic endowments and certain basic non-genetic traits are essential properties defining us as individuals and hence not properly described as a mere matter of luck (170ff.).

Incorporating the ideal of equality of opportunity on the one hand and the ethos of individual choice and responsibility on the other, Mulli- 
gan claims that meritocracy incorporates the best aspects of both egalitarianism and libertarianism and presents a viable alternative to these accounts (4). This alternative is not only theoretically interesting, but, according to Mulligan, it also has the potential of fixing the "broken, hyperpartisan politics" of the United States (3). After all, the notion that everyone can make it, regardless of race or gender, as long as he is willing to work hard for it, is the very core of the American Dream (12ff.) and according to empirical studies, the notion of desert plays a pivotal role in how people think about justice (43-55). In this respect, meritocracy seems utterly feasible and although the proposed policy measures may not yield political support in the short run, it is well possible that they do so in the long run. Mulligan's claims as to the status of his account are not unambiguous, though, since he claims to be developing a feasible theory (33, $176)$, but then again calls his account "an unabashedly utopian vision" (28) and situates it in the realm of ideal theory (33).

\section{CRITICAL ASSESSMENT}

Justice and the Meritocratic State tackles a timely issue and incorporates widely shared intuitions about just distributions of economic goods. Mulligan enriches the contemporary literature on desert and argues against the claim that, in the end, nothing is truly deserved. A great strength of the book is the fact that Mulligan bites the bullet when it comes to policies necessary to implement fair equality of opportunity. That being said, I regard the argument for merit-based hiring and remuneration as ultimately unconvincing. Even if we grant that the most meritorious person has a moral claim to be hired, the concept of 'merit' is vague so that in actual hiring processes, the question of who the most meritorious candidate is cannot be answered objectively. But even if we could do so, it remains unclear where the moral claim of the most meritorious candidate comes from, especially as this claim disregards the reasonable interests of the employer. Beyond that, the policies necessary for implementing a level of fair equality of opportunity sufficient to legitimize hiring, remuneration, and even the provision of a social safety-net on desert and merit are substantial and I wonder whether they are actually desirable.

\section{Merit}

As said above, Mulligan assumes that "once a context is fixed, it is usually plain what constitutes merit" (102). Yet, this is not the case, as for in- 
stance Deborah Hellman (2008, 97-101) has pointed out. The proper definition of merit hinges on the conception of the position at stake, which can be highly controversial. What, for instance, are the necessary qualifications of a doctor (Hellman 2008, 98ff.)? Medical knowledge, technical skills, and a certain intelligence may be quite uncontroversial, but what about empathy, modesty, and compassion? What about fitting into the team? And how ought these different dimensions to be weighed? In the examples given, Mulligan endorses a narrow conception of the positions and qualifications in question. A third baseman, for instance, must have quick reflexes, a powerful arm, and hitting ability (102). But what if a baseball player were popular in part for his looks and this popularity drove the ticket sales up (Hellman 2008, 97ff.)? Is it entirely implausible to describe the job of a professional baseball player as "being able to hit, run, and field well" (Hellman 2008, 98) plus "being able to entertain the fans'? As Hellman maintains, there is no reason to restrict the concept of merit in this way, and it is very unlikely that the authorities envisioned by Mulligan will reach a consensus on the issues.

We get a hint at the reason why Mulligan clings to a very narrow concept of merit-the common sense conception of merit, to use Hellman's terms - in his discussion of a modified version of Nozick's Wilt Chamberlain example (147ff.). Suppose the fans lose interest in Wilt and get fond of the quirky waterboy Bonzo and his funny behavior at the sideline instead. The management decides to replace Wilt by Bonzo, offering Wilt the poorly paid position of the waterboy. Mulligan considers this decision grossly unfair:

Wilt decided to take advantage of his natural talents and devote himself, through years of hard work, to excellence in basketball. His planof-life centered on this devotion, and he had a reasonable expectation that it would not be frustrated by the whims of the basketball-watching public. But now Wilt, who has done nothing wrong and everything right, finds his professional and financial futures frustrated. (148)

But what if Wilt loses his job because people just stop finding basketball interesting and become fans of hockey, instead? Not being a 'whim', does this change in demand patterns present an injustice as well? Mulligan argues that there is a "common sense distinction" between subjugating one's life-plans to reasonable preferences expressed on the market on the one hand, and depraved "tastes" of others on the other (148). But where is the normative difference and who decides what depraved tastes are? 
Here, the perfectionist dimension of meritocracy seems to lurk in the background, but I cannot see how it is supposed to guarantee that the preferences expressed on the market are 'reasonable'. In addition, the fact that Wilt had "reasonable expectation[s]" that his effort would not be for nothing cannot ground any entitlement to a certain position or income on his part (148). For one thing, this would only be the case once a meritocracy is in place; for another, here an argument as to why merit should be the basis on which these expectations are formed is required (Segall 2012, 33).

The quoted passage again appeals to the pivotal role of individual responsibility and the possibility of taking one's life in one's own hands within meritocracy. Mulligan is convinced that "setting differences in opportunity aside-the single biggest determinant of success across contexts is brute hard work" (139). This is only partly true at most. For one thing, as argued in the previous paragraph, whether 'hard work' ever pays depends in large part on the preferences of others which are not foreseeable in the long run. Whether one's skills are valued by society depends in part on their scarcity which is outside one's control as well (Hellman 2008, 109). Perhaps most importantly, although the most successful people will almost certainly have worked hard, given the fierce competition in most areas, they would not have become the most successful people without luck (Frank 2016). This means that there are probably a lot of very talented and hardworking people out there who have formed legitimate expectations and have done nothing wrong but were not hired for one of the scarce positions they strived for-academia is a case in point. Highlighting the role of luck takes the edge off Mulligan's narrative of hard work, responsibility, and control. Merit may be a necessary condition for being hired and earning an appropriate income, but it is certainly not a sufficient condition. In addition, acknowledging the central role of good and bad luck in one's life leads both to more humility as to one's own achievements and to more empathy with those who are less successful, as empirical studies confirm (Frank 2016, 93-103; and the references in Mark 2019).

\section{Equality of Opportunity}

Mulligan claims that once fair equality of opportunity is established and formal equality prevails against this background, "then everyone gets her economic deserts" (72). Under the reign of merit, "racism, sexism, and other biases" will vanish (28), and it is the government's task to guarantee 
"that citizens are not discriminated against on the grounds irrelevant from the point of view of merit" (74, see also 102). Yet, I doubt that equality of opportunity will eradicate unjust inequalities to the extent necessary for getting meritocracy off the ground. Even such revolutionarysounding examples such as universal health care, investment in early education, and a substantial inheritance tax will leave a lot of background inequalities in place. For instance, as long as the institution of the family as such is not challenged, there will remain differences as to whether children are raised by caring and loving parents and even if substantive redistribution took place, there would remain differences regarding social and cultural capital (McNamee 2018, 69-88). When it comes to racism and sexism, Mulligan seems to underestimate how pervasively these systems of oppression are embedded in and are at the same time reinforced by culture. As Anderson (2010) argues, implicit, sometimes even benign, cognitive biases-such as ingroup favoritism or shared reality bias-in combination with geographical segregation lead to the emergence and consolidation of unjust group inequalities. Although the policy measures proposed by Mulligan would probably ameliorate the situation, the stigmatization and discrimination against racialized groups would arguably require more encompassing measures.

In fact, it is not even clear whether a focus on merit necessarily leads to just hiring practices. For one thing, what is "irrelevant from the point of view of merit" $(74,101 \mathrm{ff}$.) again depends on the specific definition of merit and the respective position (Halldenius 2018). Sex, for instance, may be a legitimate qualification for a position in some cases but an illegitimate one in others. To take an example from Halldenius (2018, 110), imagine that a shelter for battered women were searching for a therapist. Would it be unjust if they wanted to hire only women? Issues such as this are discussed in the literature under the heading of "reaction qualifications", a topic Mulligan only deals with at the margins (114ff.), but which is far more complex than he presents it and, I think, crucial to his argument (see Mason 2017; Goff 2018, 307). Neglecting the employer's reasonable interests in certain reaction qualifications of the applicants, the meritocratic hiring principle is very lopsided.

Beside the problem of reaction qualifications, equality of opportunity plus merit-based hiring can lead to injustices for other reasons as well. As Schouten $(2018,188)$ points out, inequalities in labor market outcomes "are in large part explained by women's continued responsibility for the great bulk of the caregiving and domestic labor necessary to sustain the 
home and family". Women are thus less likely to accumulate as much "human capital' as men (Hellman 2008, 110ff.). Ameliorating this inequality would require policy interventions in the socialization process during which gender specific preferences, ambitions, and behaviors are conveyed. ${ }^{1}$

Mulligan might respond that a system of fair equality of opportunity would eradicate all the mentioned biases and inequalities, but my point is to stress that these measures would have to be quite radical and would limit personal liberties substantially, and I wonder whether this is an attractive ideal to strive for. Mulligan recognizes that no implemented system of fair equality of opportunity will ever be perfect (180) and I am not saying that we should not strive for equality of opportunity. My point is that since we are far away from such a situation, an economic system which attributes all of the responsibility for an individual's economic fate to the individual, distributes economic goods strictly based on merit and restricts the social safety net to the deserving poor cannot be justified. In this respect, Mulligan's meritocracy is indeed unabashedly utopian.

At this point a pragmatic argument may be allowed. Given that we are far from a system of equality of opportunity, I wonder whether making merit the center of a theory of distributive justice is a prudent choice. To summarize some empirical findings from Mark (2019), believing that one deserves one's social position and wealth on the basis of merit "makes people more selfish, less self-critical and even more prone to acting in discriminatory ways" (Mark 2019; see also McNamee 2018, 132; Frank 2016, xiv, 90). Thus, psychologically, a belief in merit may undermine the willingness to establish conditions of equality of opportunity in the first place. The cultivation of humility, gratefulness, and empathy with those who have not been so lucky as oneself may be a better way to enhance justice.

To conclude, I really enjoyed reading the book and engaging with its arguments since it raises a lot of interesting issues. But I regard the central concepts of merit and equality of opportunity as well as the normative argument for merit-based hiring and income as underdeveloped. Also, the issue of how we get from our non-ideal situation to a meritocracy as envisaged by Mulligan, deserves further attention. All in all, I

\footnotetext{
${ }^{1}$ Referring to two recent empirical studies, Mulligan ventures the claim that "clearly", in academia, "bias against women has been eliminated" (215n3). In the light of a legion of studies suggesting otherwise (see Valian 2005 and, regarding philosophy, Leuschner 2019 , and the references therein), this is a very optimistic verdict, to say the least.
} 
wholeheartedly recommend the book to anyone interested in economic justice!

\section{REFERENCES}

Anderson, Elizabeth. 2010. The Imperative of Integration. Princeton, NJ: Princeton University Press.

Cavanagh, Matt. 2002. Against Equality of Opportunity. Oxford: Oxford University Press.

Daniels, Norman. 1978. "Merit and Meritocracy." Philosophy \& Public Affairs 7 (3): 206223.

Frank, Robert. 2016. Success and Luck: Good Fortune and the Myth of Meritocracy. Princeton, NJ: Princeton University Press.

Goff, Sarah. 2018. "Discrimination and the Job Market." In The Routledge Handbook of the Ethics of Discrimination, edited by Kasper Lippert-Rasmussen, 301-311. Oxon: Routledge.

Halldenius, Lena. 2018. "Discrimination and Irrelevance." In The Routledge Handbook of the Ethics of Discrimination, edited by Kasper Lippert-Rasmussen, 108-118. Oxon: Routledge.

Hellman, Deborah. 2008. When is Discrimination Wrong? Cambridge, MA: Harvard University Press.

Leuschner, Anna. 2019. "Why So Low? On Indirect Effects of Gender Bias in Philosophy." Metaphilosophy 50 (3): 231-249.

Mark, Clifton. 2019. "A Belief in Meritocracy is not Only False: It's Bad for You.” Aeon. Accessed September 10, 2019. https://aeon.co/ideas/a-belief-in-meritocracy-is-notonly-false-its-bad-for-you.

Mason, Andrew. 2017. “Appearance, Discrimination, and Reaction Qualifications.” The Journal of Political Philosophy 25 (1): 48-71.

McNamee, Stephen J. 2018. The Meritocracy Myth. 4th edition. London: Rowman \& Littlefield.

Moles, Andres. 2018. "Discrimination and Desert." In The Routledge Handbook of the Ethics of Discrimination, edited by Kasper Lippert-Rasmussen, 119-131. Oxon: Routledge.

Segall, Shlomi. 2012. "Should the Best Qualified be Appointed?" Journal of Moral Philosophy 9 (1): 31-54.

Schouten, Gina. 2018. "Discrimination and Gender." In The Routledge Handbook of the Ethics of Discrimination, edited by Kasper Lippert-Rasmussen, 185-195. Oxon: Routledge.

Valian, Virginia. 2005. "Beyond Gender Schemas: Improving the Advancement of Women in Academia.” Hypatia 20 (3): 198-213.

Andrea Klonschinski is a postdoctoral researcher at the Department of Philosophy at Kiel University. Her research focuses especially on the concept of utility in economics, on the ethics of discrimination, and on women in philosophy. She is the author of the book The Economics of Resource Allocation in Health Care: Cost-Utility, Social Value, and Fairness (Routledge, 2016).

Contact e-mail: <klonschinski@philsem.uni-kiel.de> 